\title{
Caloric Restriction Experience Reprograms Stress and Orexigenic Pathways and Promotes Binge Eating
}

\author{
Diana E. Pankevich, Sarah L. Teegarden, Andrew D. Hedin, Catherine L. Jensen, and Tracy L. Bale \\ Department of Animal Biology, University of Pennsylvania, Philadelphia, Pennsylvania 19104
}

\begin{abstract}
Long-term weight management by dieting has a high failure rate. Pharmacological targets have focused on appetite reduction, although less is understood as to the potential contributions of the stress state during dieting in long-term behavioral modification. In a mouse model of moderate caloric restriction in which a $10-15 \%$ weight loss similar to human dieting is produced, we examined physiological and behavioral stress measures. After 3 weeks of restriction, mice showed significant increases in immobile time in a tail suspension test and stress-induced corticosterone levels. Increased stress was associated with brain region-specific alterations of corticotropin-releasing factor expression and promoter methylation, changes that were not normalized with refeeding. Similar outcomes were produced by high-fat diet withdrawal, an additional component of human dieting. In examination of long-term behavioral consequences, previously restricted mice showed a significant increase in binge eating of a palatable high-fat food during stress exposure. Orexigenic hormones, melanin-concentrating hormone $(\mathrm{MCH})$ and orexin, were significantly elevated in response to the high-fat diet only in previously restricted mice. Furthermore, administration of the MCH receptor-1 antagonist GSK-856464 [4-(4-ethyl-5-methylsulfanyl-1,2,4-triazol3-yl)pyridine] significantly reduced total caloric intake in these mice during high-fat access. These results reveal reprogramming of key central pathways involved in regulating stress responsivity and orexigenic drives by moderate caloric restriction experience. In humans, such changes would be expected to reduce treatment success by promoting behaviors resulting in weight regain, and suggest that management of stress during dieting may be beneficial in long-term maintenance.
\end{abstract}

\section{Introduction}

Dieting as a mode of behavioral modification in weight management has proven to have little long-term success with a $>80 \%$ failure rate (Wing and Phelan, 2005). The elevated weight regain and increased risk for diabetes and related metabolic disease after dieting make identification of novel therapeutic targets critical (Lissner et al., 1991; Brownell and Rodin, 1994; Guagnano et al., 2000). Current treatments predominantly focus on appetite reduction, although less is known regarding the central mechanisms contributing to treatment resistance and failure, especially that of the involvement of stress pathways.

As stress and the stress hormone corticotropin-releasing factor (CRF) are known promoters of increased consumption of calorically dense foods, reprogramming of stress circuitry may be a central mechanism driving repeated dieting, or the "yo-yo" effect, resulting in an increased risk for greater weight gain and later obesity (Epel et al., 2001; Dallman et al., 2006; Amigo and Fernández, 2007; Teegarden and Bale, 2008). Stress-induced activation of the hypothalamic-pituitary-adrenal (HPA) stress axis and release of CRF increases reward-seeking behaviors (Dallman et al., 2005; Ghitza et al., 2006). CRF antagonism in the bed

Received April 16, 2010; revised Sept. 15, 2010; accepted Sept. 16, 2010.

These studies were supported by funding from University of Pennsylvania Diabetes Center National Institutes of Health Grant DK019525, Health Research Formula Fund, and AstraZeneca (Wilmington, DE). We thank Kendall Carlin for technical assistance.

Correspondence should be addressed to Dr. Tracy L. Bale, 201E Vet, 6046, Department of Animal Biology, University of Pennsylvania, 3800 Spruce Street, Philadelphia, PA 19104. E-mail: tbale@vet.upenn.edu.

DOI:10.1523/JNEUROSCI.1955-10.2010

Copyright $\odot 2010$ the authors $\quad 0270-6474 / 10 / 3016399-09 \$ 15.00 / 0$ nucleus of the stria terminalis (BNST) decreases stress-induced drug reinstatement, whereas injection of CRF promotes drug seeking, demonstrating an intersection of stress and reward pathways (Erb and Stewart, 1999; Koob, 2009). Evidence from these and other studies suggests that stress plays a critical role in increasing consummatory behavior of rewarding substances, including calorically dense foods (Shaham et al., 2000; Sinha, 2001; Wang et al., 2005; Dallman et al., 2006; Teegarden and Bale, 2008).

We hypothesized that previous restriction experience would produce changes in stress neurocircuitry leading to a subsequent increased stress sensitivity and tendency to overconsume high-fat food. To examine this hypothesis, we compared physiological and behavioral stress responses in a mouse model of caloric restriction that produces a $10-15 \%$ reduction in body weight, levels typical of human weight loss during dieting (Redman et al., 2007; Sarwer et al., 2009). The long-term impact and programming effect of this moderate restriction on behavioral measures and stress responsivity were determined. Mechanistically, CRF expression and promoter methylation was examined. In addition to reduced calories, a major component of human dieting is a decrease in fat content and diet palatability. We have previously shown in mice that withdrawal from a high-fat diet increases the relative stress state, and promotes reinstatement behaviors in which mice select an aversive environment to gain access to the preferred high-fat diet (Teegarden and Bale, 2007). Therefore, we similarly compared CRF expression and methylation patterns up to 8 weeks after withdrawal from a high-fat diet, demonstrating the long-term programming that occurs. 
To explore the behavioral impact of epigenetic modifications in stress circuitry on food intake, we examined binge eating of a high-fat diet after chronic stress in previously restricted mice. In addition, sensitivity to a melanin-concentrating hormone $(\mathrm{MCH})$ receptor-1 antagonist on this behavior was assessed. Together, these results may provide novel therapeutic directions by which more effective and lasting weight management treatments are designed.

\section{Materials and Methods}

Animals

All mice in these studies were males (C57BL/6J; 7-8 weeks of age) obtained from The Jackson Laboratory and individually housed on a $12 \mathrm{~h}$ light/dark schedule with food and water available ad libitum, except where otherwise noted. House chow contained $28 \%$ protein, $60 \%$ carbohydrates, and $12 \%$ fat by calories and $4.00 \mathrm{kcal} / \mathrm{g}$ (Purina Lab Diet). High-fat diet contained $20 \%$ protein, $35 \%$ carbohydrates, and $45 \%$ fat by calories and $4.73 \mathrm{kcal} / \mathrm{g}$ (Research Diets). This diet is highly preferred to house chow in C57BL/6J mice (Teegarden and Bale, 2007). All studies were done according to University of Pennsylvania University Laboratory Animal Resources and the Institutional Animal Care and Use Committee standards and guidelines.

\section{Caloric restriction}

Average daily food intake was established over $10 \mathrm{~d}$. Mice were randomly assigned to caloric restriction (Rstr), 75\% of average caloric intake, or ad libitum treatment groups (Rstr, $n=41$; ad libitum, $n=37$ ). This reduction was selected to produce $10-15 \%$ body weight loss to mimic typical diet regimens in humans. For restricted groups, preweighed house chow pellets were placed in cages $2.5 \mathrm{~h}$ before lights out for $21 \mathrm{~d}$. This schedule was used to ensure that mice had access to food before and after lights out when the majority of food consumption occurs and to avoid food entrained oscillators by allowing consumption during the dark phase (Mendoza, 2007). Body weights were recorded every 2-3 d.

\section{Leptin}

To determine the impact of caloric restriction and chow or high-fat diet refeeding on leptin levels, a blood sample was obtained at the time of killing in a subset of mice (ad libitum, $n=11$; Rstr, $n=12$ ). Samples were centrifuged, and plasma was collected and frozen at $-80^{\circ} \mathrm{C}$ until analysis. Plasma levels were measured by radioimmunoassay kit for leptin (LINCO Research). The protocol was modified to use $50 \mu \mathrm{l}$ of plasma for each assay, and each sample was assessed in duplicate. The intraassay coefficient of variation was $<6 \%$.

\section{Stress sensitivity}

Tail suspension test. The tail suspension test (TST) was administered according to standard procedure between 11:00 A.M. and 1:00 P.M. on day 19 of caloric restriction (ad libitum, $n=11$; Rstr, $n=12$ ) (McEuen et al., 2009). Briefly, each mouse was suspended by the tail at a height of 40 $\mathrm{cm}$ for $6 \mathrm{~min}$, during which immobility was measured by an experimenter blind to treatment using AnyMaze software (Stoelting). An animal was considered to be immobile when it did not show any movement and hanged passively.

HPA axis stress response. Corticosterone levels were measured in response to a 15 min restraint stress starting at 9:00 A.M. on day 21 of caloric restriction (ad libitum, $n=11$; Rstr, $n=12$ ). Mice were placed in a $50 \mathrm{ml}$ conical tube for $15 \mathrm{~min}$, and tail blood samples were obtained at $0,15,45$, and $75 \mathrm{~min}$. All samples were stored on ice until centrifuged at $5000 \mathrm{rpm}$ at $4^{\circ} \mathrm{C}$. Plasma was removed and stored at $-80^{\circ} \mathrm{C}$ until radioimmunoassay was performed. The corticosterone assay was performed according to manufacturer's instructions (MP Biomedicals). Each sample was assessed in duplicate. The minimum detection limit of the assay was $7.7 \mathrm{ng} / \mathrm{ml}$, and the intraassay coefficient of variation was $7.3 \%$.

\section{Examination of stress pathways}

Refeeding. After $21 \mathrm{~d}$ of caloric restriction, a subset of mice was refed either a high-fat or chow diet ad libitum for 1 week (ad libitum, $n=4$; Rstr, $n=5$; Rstr-chow (Refed), $n=5$; ad libitum-HF, $n=5$; Rstr-HF, $n=$
6). In addition, a subset of mice that had previously been fed chow ad libitum was given high-fat diet ad libitum for 1 week. These mice served as a dietary control for mice previously restricted and then placed on the high-fat diet. All mice were killed on the same day after 1 week of refeeding.

High-fat withdrawal. A separate cohort of mice was allowed to habituate to the facility for 2 weeks. Mice were then divided into two groups, 4 weeks of high-fat diet exposure $(n=60)$ and chow $(n=12)$. To examine the impact of varying lengths of high-fat withdrawal, the high-fat diet group was further subdivided into high-fat diet exposed (HF; $n=12$ ), or withdrawn (returned to chow) for $2,4,6$, or 8 weeks ( $n=12$ /group). The start of high-fat exposure was staggered such that all mice were killed simultaneously at the end of the withdrawal period.

TaqMan real-time PCR. Expression of individual genes after caloric restriction, refeeding, and high-fat withdrawal was assessed using TaqMan gene expression assays. Tissue punches were taken from $300 \mu \mathrm{m}$ sections using a $1 \mathrm{~mm}$ circular punch (Ted Pella). For the central nucleus of the amygdala (CeA) and BNST, punches from one hemisphere were used for RNA isolation for gene expression analyses, whereas punches from the opposing hemisphere were taken for genomic DNA isolation for bisulfite sequencing. Lateral hypothalamus ( $\mathrm{LH}$ ) tissue punches from both hemispheres were isolated for RNA. For both the CeA and BNST, three punches were isolated from each side, whereas a total of eight punches was isolated for the $\mathrm{LH}$. The areas punched correspond to areas diagramed in the Paxinos and Franklin mouse atlas (Paxinos and Franklin, 2001). Tissue was added directly to TRIzol reagent (Invitrogen) and total RNA isolation was performed with chloroform followed by isopropanol precipitation. cDNA was synthesized from 500 ng of total RNA using SuperScript First-Strand Synthesis System (Invitrogen). Changes in CRF (Mm01293920_m1), MCH (Mm01242886_m1), and orexin (Hcrt) (Mm01964030_m1) were measured using quantitative real-time PCR and TaqMan Gene Expression Assay (Applied Biosystems). $\beta$-Actin (Actb) (4352933E) served as an endogenous control for the caloric restriction studies and GAPDH (4352932E) for the high-fat withdrawal studies. The cycle threshold for the control was subtracted from the target threshold value. All samples were run in duplicate for both target gene and endogenous control. Samples were analyzed using the Applied Biosystems 7500 Fast Real-Time PCR System. The amplification profile consisted of $20 \mathrm{~s}$ denaturation at $95^{\circ} \mathrm{C}$, and 40 cycles of $3 \mathrm{~s}$ at $95^{\circ} \mathrm{C}$ and $30 \mathrm{~s}$ at $60^{\circ} \mathrm{C}$. The cycle number at threshold (CT value) was used for calculations of relative mRNA levels. The CT value of each target gene was normalized by subtracting the endogenous control CT value (raw $\Delta \mathrm{C}_{\mathrm{T}}$ value). The $\Delta \mathrm{C}_{\mathrm{T}}$ value was converted to fold change by calculating $2^{(-\Delta \mathrm{CT})}$ for each sample and normalizing each value to the average for the control chow.

Analysis of DNA methylation. The impact of caloric restriction, chow refeeding, or high-fat withdrawal, on methylation status of specific CpG dinucleotides within the promoter region of mouse CRF were analyzed (McGill et al., 2006). Genomic DNA from the CeA and BNST was isolated from micropunches. Briefly, tissue was added directly to highmolecular-weight DNA extraction buffer ( $1 \mathrm{~m}$ Tris-HCl, EDTA, SDS, and water) plus RNase $\mathrm{A}$ and incubated for $1 \mathrm{~h}$ at $37^{\circ} \mathrm{C}$ followed by proteinase $\mathrm{K}$ addition and incubation overnight at $55^{\circ} \mathrm{C}$. Next, a chloroform/ isoamyl alcohol extraction was performed before DNA was precipitated with sodium acetate and glycogen at $-80^{\circ} \mathrm{C}$ for $1 \mathrm{~h}$ followed by centrifugation (10 min, 12,000 rpm, room temperature). The pellet was saved and resuspended in TE buffer. Pyrosequencing was performed by EpigenDx as previously described (Kim et al., 2007; Liu et al., 2007). Briefly, bisulfate modification was performed converting unmethylated cytosine to uracil. The promoter sequence for the CRF gene was PCR amplified and the biotinylated product purified for pyrosequencing. Site-specific primers were designed to determine the $\mathrm{CpG}$ dinucleotide methylation status.

\section{Stress-induced binge eating}

To determine the potential impact of neurocircuitry reprogramming that occurs as a result of previous caloric restriction on binging of a palatable high-fat diet during chronic stress, we exposed mice to a limited access procedure (Teegarden and Bale, 2008). After 3 weeks of caloric 
restriction, mice were refed house chow ad libitum until restricted groups reached the same weight as controls (10 d). Limited access consisted of providing a single pellet of preweighed high-fat diet in the home cage for 1 h (3:00 P.M. to 4:00 P.M.) along with preweighed house chow. Mice were allowed $3 \mathrm{~d}$ to habituate to the high-fat diet and feeding schedule before $10 \mathrm{~d}$ of testing. On day 1 of testing, a subset of mice was exposed to chronic variable stress (CVS) throughout testing (ad libitum-Ctrl, $n=8$; ad libitum-CVS, $n=9$; Rstr-Ctrl, $n=9$; Rstr-CVS, $n=9$ ). Chronic variable stress consisted of one stressor per day for $10 \mathrm{~d}$ in an unpredictable pattern and included the following: $15 \mathrm{~min}$ restraint, $30 \mathrm{~min}$ of total darkness (three times) during the light cycle, exposure to novel objects overnight, damp bedding overnight, cage changes (three times) during the light cycle, novel noise overnight, and $15 \mathrm{~min}$ exposure to a predator odor (McEuen et al., 2009). These mild stressors were designed to not induce pain and be resistant to habituation. The amount of high-fat diet consumed within $1 \mathrm{~h}$, and after $24 \mathrm{~h}$ of house chow was measured.

\section{Reversal of high-fat diet withdrawal induced binge eating}

As we hypothesized that previously restricted mice based on their dysregulation of stress and orexigenic pathways would show a greater sensitivity to an acute treatment with the melanin-concentrating hormone receptor-1 (MCHr1) antagonist 4-(4-ethyl-5-methylsulfanyl-1,2,4triazol-3-yl)pyridine (GSK-856464), we examined caloric intake and binge eating after high-fat diet exposure and withdrawal stress. To determine whether serotonergic pathways may also be involved in the stress dysregulation in these mice, we included treatment with the selective serotonin reuptake inhibitor (SSRI) citalopram for comparison. Immediately after caloric restriction, all mice were given ad libitum access to the high-fat diet for 9 weeks and then withdrawn (returned to chow) for $10 \mathrm{~d}$. Mice were provided $3 \mathrm{~d}$ access to a preweighed high-fat pellet for $1 \mathrm{~h}(3: 00$ P.M. to 4:00 P.M.) and ad libitum access to chow (ad libitum, $n=23$; Rstr, $n=24)$. On the fourth day of this limited access, mice received an intraperitoneal injection of drug [GSK-856464 (30 mg/kg); citalopram $(20 \mathrm{mg} / \mathrm{kg})]$ or vehicle $1 \mathrm{~h}$ before the start of limited access to the high-fat pellet (ad libitum-VEH, $n=7$; ad libitum-GSK, $n=8$; ad libitum-CIT, $n=8$; Rstr-VEH, $n=8$; Rstr-GSK, $n=8$; Rstr-CIT, $n=8$ ). High-fat diet consumption within $1 \mathrm{~h}$ was measured, in addition to $24 \mathrm{~h}$ of chow and total calories calculated.

\section{Statistical analysis}

Differences in weight and plasma leptin levels were analyzed by either Student's $t$ test or one-way ANOVA. Corticosterone data were analyzed using two-way repeated-measures ANOVA for restriction and time. For TST, data were analyzed using Student's $t$ test. For CRF gene expression after caloric restriction or high-fat withdrawal, data were analyzed using a one-way ANOVA with Fisher's PLSD post hoc tests. Methylation data were analyzed using a one-way ANOVA to determine difference between groups within each $\mathrm{GpC}$ site and overall methylation across the promoter. For stress-induced $10 \mathrm{~d}$ binge eating, data were analyzed using a one-way repeated-measures ANOVA with control and CVS groups analyzed separately. Total caloric intake data during binge eating were analyzed using Student's $t$ test. For gene expression analysis of orexigenic hormones, fold changes were computed relative to ad libitum chow controls and a two-way ANOVA was used with Fisher's PLSD post hoc tests. For reversal of high-fat withdrawal-induced binge eating, data from the first $3 \mathrm{~d}$ were analyzed using a one-way repeated-measures ANOVA, and data from the fourth day were analyzed using a two-way ANOVA with Fisher's PLSD post hoc tests. All statistical analysis was performed using SigmaStat (Systat Software).

\section{Results}

\section{Caloric restriction induced stress sensitivity}

Body weights and leptin

Male mice calorically restricted to $75 \%$ of their normal chow intake show significant weight loss at the end of 3 weeks of restriction. Over the 3 week period, the control mice gained weight $\left.t_{(20)}=-4.294 ; p \leq 0.001\right)$, whereas restricted mice lost weight $\left(t_{(22)}=8.214 ; p \leq 0.001\right)$; thus, at the end of restriction, the weights were significantly different $\left(t_{(21)}=11.815 ; p \leq 0.001\right)$.
Table 1. Body weights and leptin levels after caloric restriction

\begin{tabular}{lllc}
\hline & Start BW $(\mathrm{g})$ & End BW $(\mathrm{g})$ & Leptin $(\mathrm{ng} / \mathrm{ml})$ \\
\hline Ad libitum & $25.7 \pm 0.2$ & $27.3 \pm 0.3$ & $10.4 \pm 1.1$ \\
Rstr & $26.3 \pm 0.3$ & $22.7 \pm 0.3^{*}$ & $7.0 \pm 0.5^{*}$ \\
\hline
\end{tabular}

BW, Body weight.

*Effect of caloric restriction (weight, $p \leq 0.001$; leptin, $p<0.05$ ).
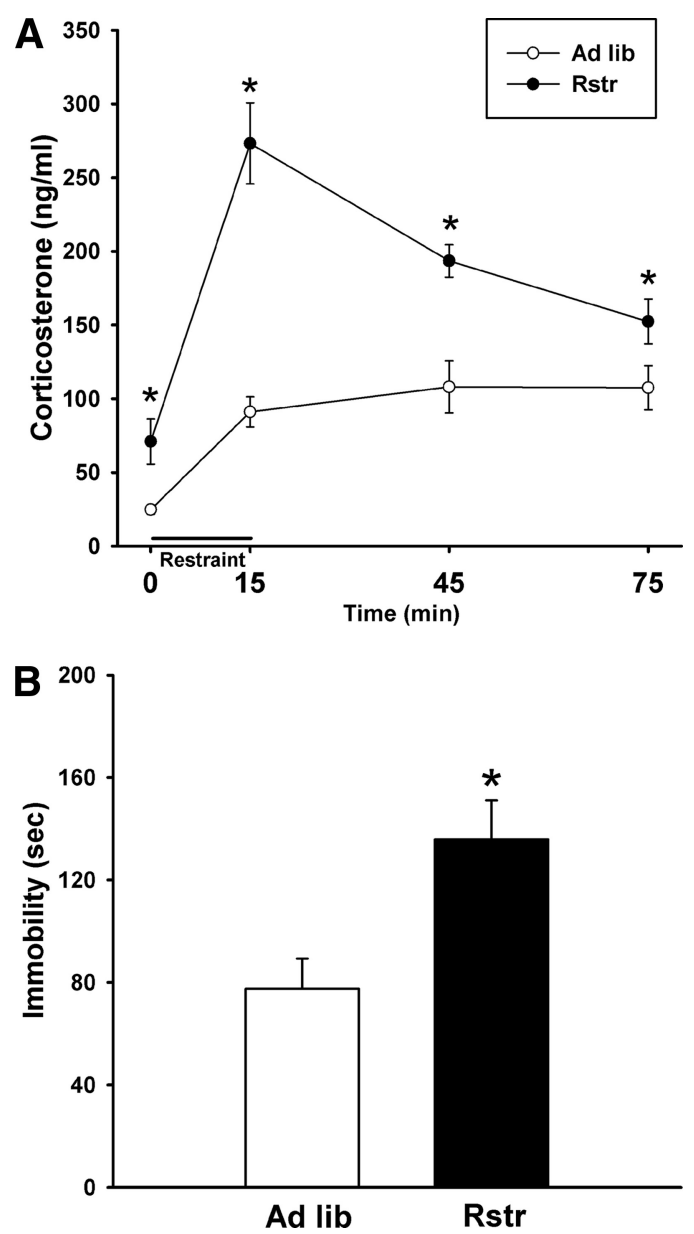

Figure 1. Moderate calorie restriction promotes an increased stress state. $\boldsymbol{A}$, Restraint stressinduced HPA axis corticosterone response was significantly elevated in calorically restricted (Rstr) mice (ad libitum, $n=11$; Rstr, $n=12$ ) ( $\left.{ }^{*} p<0.05\right)$. B, Maladaptive behavioral responses were detected in a tail suspension test in which restricted mice showed a significant increase in time spent immobile compared with ad libitum (ad libitum) fed mice $(n=11-12)$. Data are mean \pm SEM.

Plasma leptin levels were measured from a subset of mice killed at the end of the 3 week restriction period. Calorically restricted mice had significantly lower levels of leptin $\left(t_{(8)}=2.715 ; p=\right.$ 0.03) (Table 1).

\section{HPA axis stress response}

To evaluate the physiological stress response after caloric restriction, mice were restraint stressed and a time course of corticosterone levels was measured. Calorically restricted mice showed a significantly increased stress response $\left(F_{(1,21)}=26.649 ; p<\right.$ 0.001 ) with higher basal corticosterone levels as found by post hoc tests $(p<0.05)$. In addition, this group had a higher maximal rise in response to the $15 \mathrm{~min}$ restraint $(p<0.001)$ and a delayed stress recovery ( $45 \mathrm{~min}, p<0.001 ; 75 \mathrm{~min}, p=0.05$ ) (Fig. $1 A$ ). 

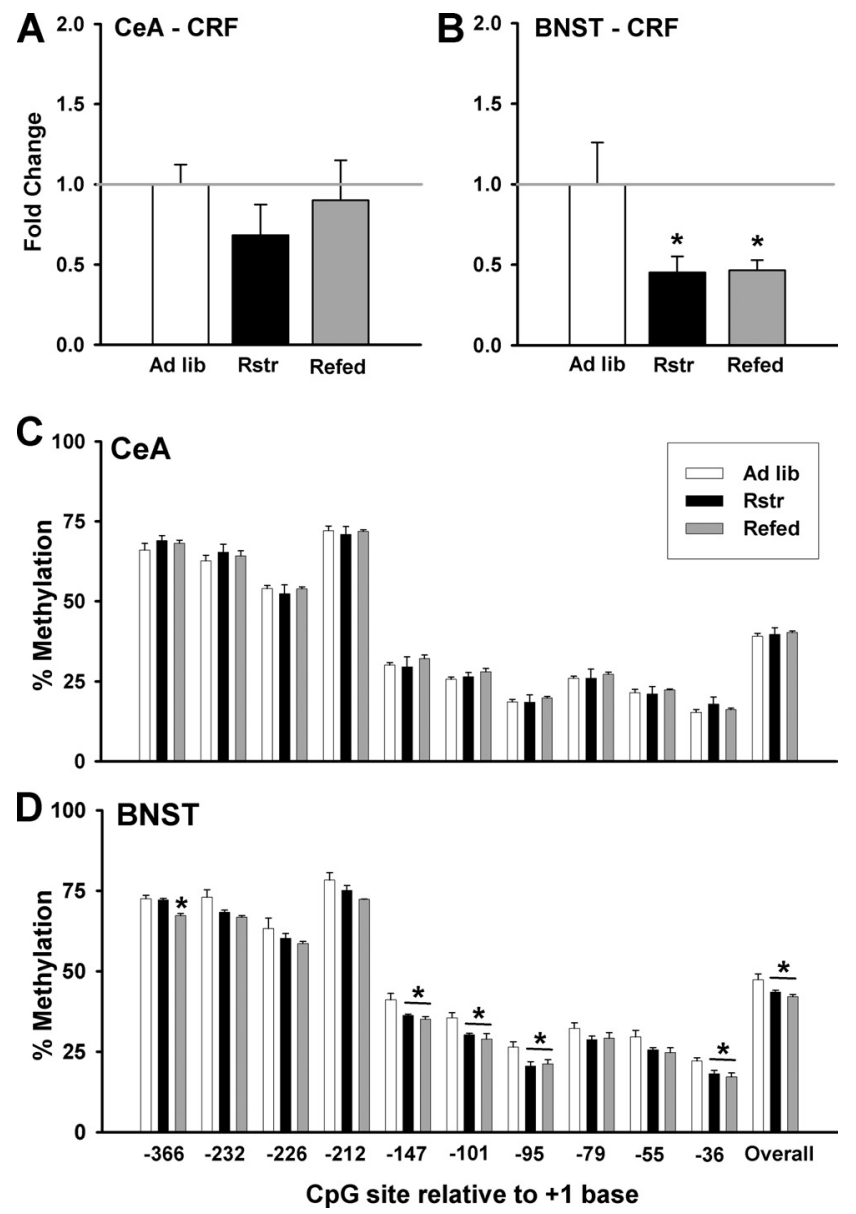

Figure 2. Moderate caloric restriction induces changes in stress pathways. $A$, There were no significant changes in CRF gene expression levels in the CeA compared with controls. B, CRF levels in the BNST were significantly decreased after 3 weeks of caloric restriction and remained reduced after 1 week of refeeding with chow (Refed) $\left({ }^{*} p<0.01\right)$. C, There were no changes in methylation of the CRF promoter at individual cytosines in the CeA. D, In the BNST, there were significant decreases in methylation at multiple cytosines in calorically restricted mice that remained down after 1 week chow refeeding (Refed) ( ${ }^{*}$ post hoc, $p<0.05$ ) [ad libitum, $n=4$; Rstr, $n=4$; Rstr-Chow (Refed), $n=4$ ]. In addition, there was an overall effect of caloric restriction on methylation $(p<0.05)$. Data are mean \pm SEM.

Tail suspension test

To assess stress-induced behavioral responses, the tail suspension test was administered after $19 \mathrm{~d}$ of caloric restriction. There was a significant effect on time spent immobile $\left(t_{(21)}=-2.989 ; p<\right.$ $0.01)$ with the calorically restricted group spending more time immobile than controls (Fig. $1 B$ ).

\section{CRF expression}

The impact of previous caloric restriction on gene expression changes in stress pathways was assessed using quantitative TaqMan reverse transcription (RT)-PCR. CRF levels in the CeA were unchanged with caloric restriction or chow refeeding after restriction (Fig. 2A). CRF levels in the BNST were significantly different between groups $\left(F_{(2,13)}=8.335 ; p<0.01\right)$ (Fig. $2 B$ ). Caloric restriction significantly decreased BNST CRF $(p<0.01)$, and CRF remained reduced after refeeding $(p<0.01)$.

\section{DNA methylation of CRF promoter}

As refeeding did not normalize CRF expression in the BNST, we examined epigenetic changes in promoter methylation. Similar to CRF expression, no differences in methylation were detected in the CeA (Fig. 2C). Within the BNST, there was a significant re-
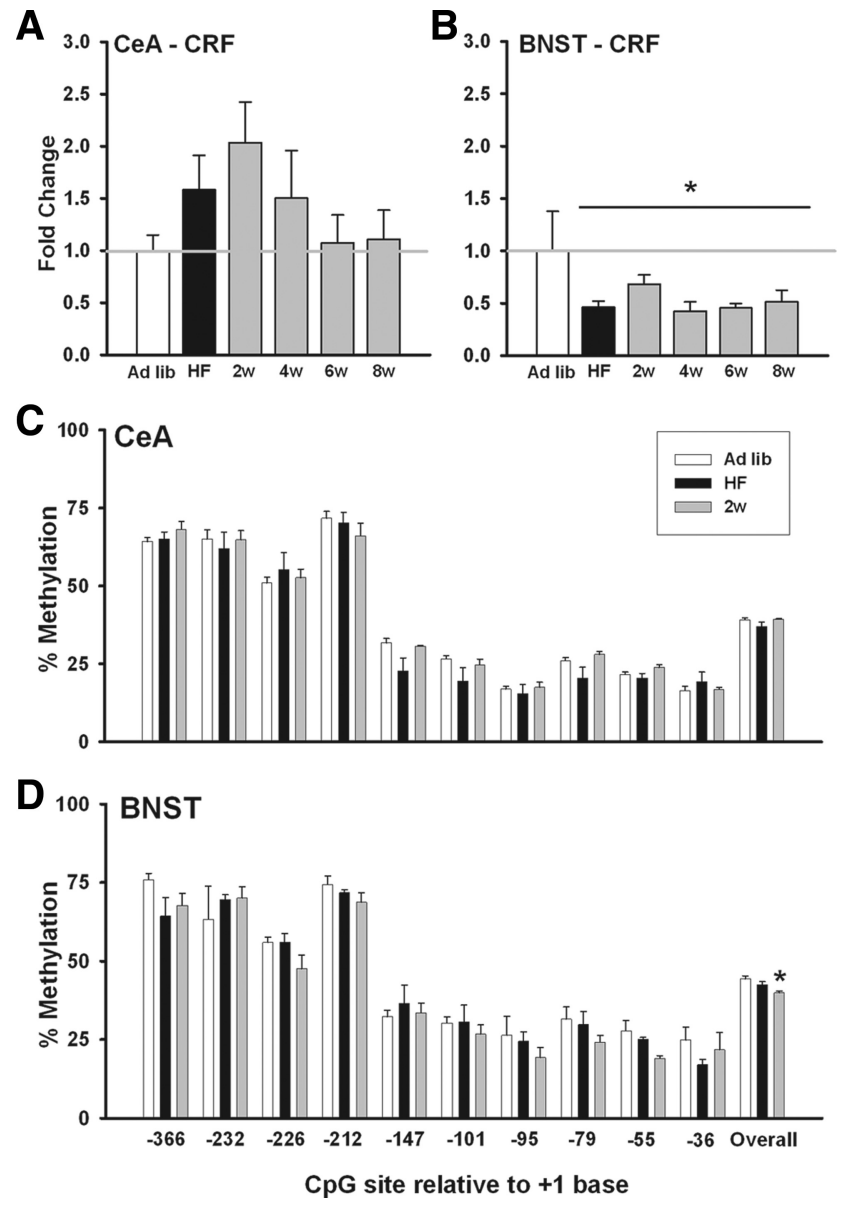

Figure 3. High-fat withdrawal induces changes in stress pathways. $A$, There were no significant changes in CRF gene expression levels in the CeA compared with controls after high-fat exposure and subsequent withdrawal $(n=12)$. $\boldsymbol{B}$, CRF levels in the BNST were significantly decreased by high-fat diet exposure and remained reduced for at least 8 weeks after withdrawal $(n=12)\left({ }^{*} p<0.01\right) . C$, In the CeA, there were no changes in methylation of the CRF promoter at individual cytosines or overall $(n=5)$. D. There was an overall significant decrease in methylation of the CRF promoter in the BNST $(n=5)$ after high-fat withdrawal $\left({ }^{*} p<0.05\right)$. Data are mean \pm SEM.

duction in methylation during caloric restriction that was not normalized during refeeding at 6 of the 10 cytosines within the reported CpG island $\left[-366\right.$ bp: $F_{(1,11)}=17.066, p<0.001(p<$ 0.001 , post hoc for ad libitum vs Refed and Rstr vs Refed); -147 bp: $F_{(1,11)}=6.126, p<0.05$ ( $p<0.05$, post hoc for ad libitum vs both Rstr and Refed); -101 bp: $F_{(1,11)}=6.509, p<0.05(p<$ 0.05 , post hoc for ad libitum vs both Rstr and Refed); $-95 \mathrm{bp}$ : $F_{(1,11)}=4.839, p<0.05$ ( $p<0.05$, post hoc for ad libitum vs both Rstr and Refed); -36 bp: $F_{(1,11)}=5.399, p<0.05(p<0.05$, post hoc for ad libitum vs both Rstr and Refed)]. In addition, there was an overall effect of caloric restriction without normalization of the CRF promoter $\left(F_{(2,11)}=5.992 ; p<0.05\right)$ (Fig. $\left.2 D\right)$.

\section{High-fat withdrawal reprogramming of stress pathways}

CRF expression

The impact of high-fat diet exposure and varying lengths of withdrawal on gene expression changes in stress pathways was assessed using quantitative TaqMan RT-PCR. CRF levels in the $\mathrm{CeA}$ showed a nonsignificant peak of gene expression at 2 weeks after withdrawal and returned to baseline by 6 weeks (Fig. $3 A$ ). CRF levels in the BNST were significantly decreased by high-fat 
Table 2. Body weights after high-fat binge-eating

\begin{tabular}{llll}
\hline & End restriction $(\mathrm{g})$ & Refed BW $(\mathrm{g})$ & End Binge BW $(\mathrm{g})$ \\
\hline Ad libitum & $24.5 \pm 0.3$ & $26.9 \pm 0.4$ & $27.4 \pm 0.3$ \\
Rstr & $23.0 \pm 0.3^{*}$ & $26.6 \pm 0.4$ & $27.1 \pm 0.4$ \\
\hline
\end{tabular}

BW, Body weight.

*Effect of caloric restriction ( $p \leq 0.001$ ).

diet exposure and remained reduced for at least 8 weeks after withdrawal $\left(F_{(5,24)}=4.4 ; p<0.01\right)$ (Fig. $\left.3 B\right)$.

DNA methylation of CRF promoter

As CRF expression in the BNST remained reduced for at least 8 weeks after the end of high-fat diet exposure, we examined epigenetic changes in promoter methylation. Similar to CRF gene expression, no differences in methylation were detected in the CeA (Fig. 3C). In contrast, in the BNST, we observed an overall effect of diet treatment on methylation of the CRF promoter $\left(F_{(2,12)}=4.4 ; p<0.05\right)$, which post hoc testing revealed to be driven by a reduction in methylation in the withdrawal group relative to controls $(p<0.01)$ (Fig. 3D).

\section{Stress-induced binge eating}

Body weights

After caloric restriction, control mice weighed significantly more than the calorically restricted mice $\left(t_{(34)}=6.971 ; p \leq 0.001\right)$. After 3 weeks of restriction, mice were placed back on ad libitum chow (refeeding) until the significant weight difference between control and restricted mice were no longer present before the start of limited access to ensure that intake differences were not attributable to differences in weight. Weights were continually monitored during limited access as well, and there were no significant differences during or at the end of these trials (Table 2).

\section{Limited access}

To determine whether the increased stress responsivity and changes in CRF epigenetic programming in the BNST after calorie reduction would result in increased stress-induced binge eating, mice were provided limited access to a high-fat diet during CVS. Under basal nonstress conditions (Ctrl), there were no significant differences between groups in the calories from high-fat diet consumed over the course of testing $\left(F_{(1,15)}=0.881 ; p=\right.$ 0.363 ) (Fig. $4 A$, left panel) or as a percentage of total calories consumed (Fig. $4 \mathrm{~B}$, left panel). All mice displayed binge eating, consuming $\sim 50 \%$ of their total $24 \mathrm{~h}$ caloric intake during the $1 \mathrm{~h}$ of access, demonstrating the overall preference mice have for the high-fat food (Teegarden and Bale, 2008). During chronic variable stress, mice that had undergone previous caloric restriction consumed significantly more calories than control mice over the $10 \mathrm{~d}$ of testing $\left(F_{(1,16)}=4.479 ; p<0.05\right)$ (Fig. $4 C$, left panel). There was also a main effect of day $\left(F_{(1,9)}=7.144 ; p<0.001\right)$, with intake increasing over the course of testing. Over the entire $10 \mathrm{~d}$ of testing, previously calorically restricted mice consumed significantly greater total amounts of high-fat diet than control mice $\left(t_{(16)}=-2.133 ; p<0.05\right)$ (Fig. $4 C$, right panel). Overall, there were no significant differences in the total amount of calories consumed, high-fat and chow diet, by all groups (data not shown). Under chronic variable stress, the percentage of calories from the high-fat diet is significantly greater for calorically restricted mice compared with controls $\left(F_{(1,16)}=5.581 ; p<0.05\right)$ (Fig. $4 D$, left panel). The percentage of calories from high-fat food significantly changed over the $10 \mathrm{~d}$ of testing $\left(F_{(1,9)}=3.538\right.$; $p<0.001)$, and a significant interaction between restriction and day $\left(F_{(1,143)}=2.305 ; p=0.02\right)$. Over the $10 \mathrm{~d}$ of testing, the total
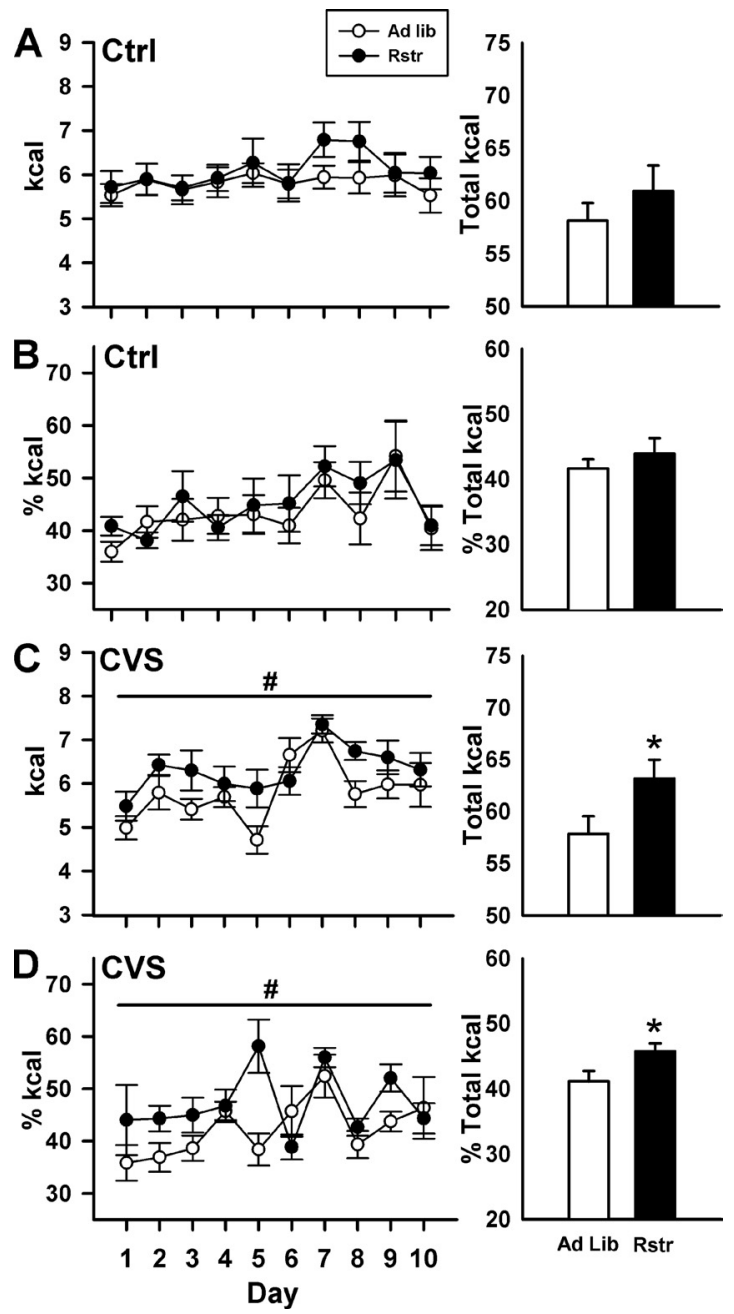

Figure 4. Increased stress induced binge-like eating of a high-fat diet after 3 weeks of caloric restriction. $\boldsymbol{A}, \boldsymbol{B}$, Under control conditions, there were no differences in calories from high-fat diet over the course of the $10 \mathrm{~d}$ of testing or as a percentage of calories. C, Left panel, During CVS, calorically restricted mice consumed significantly more calories of high-fat diet compared with controls (ad libitum) over the $10 \mathrm{~d}$ of testing ( ${ }^{\#} p<0.05$ ). C, Right panel, Calorically restricted mice consumed significantly greater total amounts of high-fat diet $\left({ }^{*} p<0.05\right)$. D, In addition, the total percentage of calories from high fat was significantly greater in the restricted mice $\left({ }^{\# * *} p<0.05\right)$ (ad libitum-Ctrl, $n=8$; ad libitum-CVS, $n=9$; Rstr-Ctrl, $n=9 ;$ Rstr-CVS, $n=9$ ). Data are mean \pm SEM.

percentage of high-fat calories consumed was significantly greater in the calorically restricted mice $\left(t_{(16)}=-2.312 ; p<\right.$ 0.05) (Fig. 4D, right panel).

\section{Orexigenic gene expression in response to high-fat exposure} Body weights

At the end of caloric restriction, control mice weighed significantly more than the restricted mice $\left(t_{(25)}=2.434 ; p<0.05\right)$. Refeeding for 1 week on high-fat diet did not significantly increase weights (Table 3 ).

$\mathrm{MCH}$ and orexin expression

To determine molecular mechanisms that may be downstream of stress pathways driving increased high-fat intake after restriction, we examined expression of the orexigenic hormones $\mathrm{MCH}$ and orexin in the lateral hypothalamus in calorically restricted mice refed on a chow or high-fat diet. Gene expression levels of $\mathrm{MCH}$ revealed an interaction of previous caloric restriction and diet $\left(F_{(1,12)}=6.378 ; p<0.05\right)$, in which $\mathrm{MCH}$ expression was signif- 
Table 3. Body weights after 1 week ad libitum high fat

\begin{tabular}{lll}
\hline & Start BW $(\mathrm{g})$ & End BW $(\mathrm{g})$ \\
\hline Ad libitum & $24.9 \pm 0.4$ & $26.7 \pm 1.1$ \\
Rstr & $23.8 \pm 0.2^{*}$ & $27.5 \pm 0.5$
\end{tabular}

BW, Body weight.

${ }^{*}$ Effect of caloric restriction $(p<0.05)$.
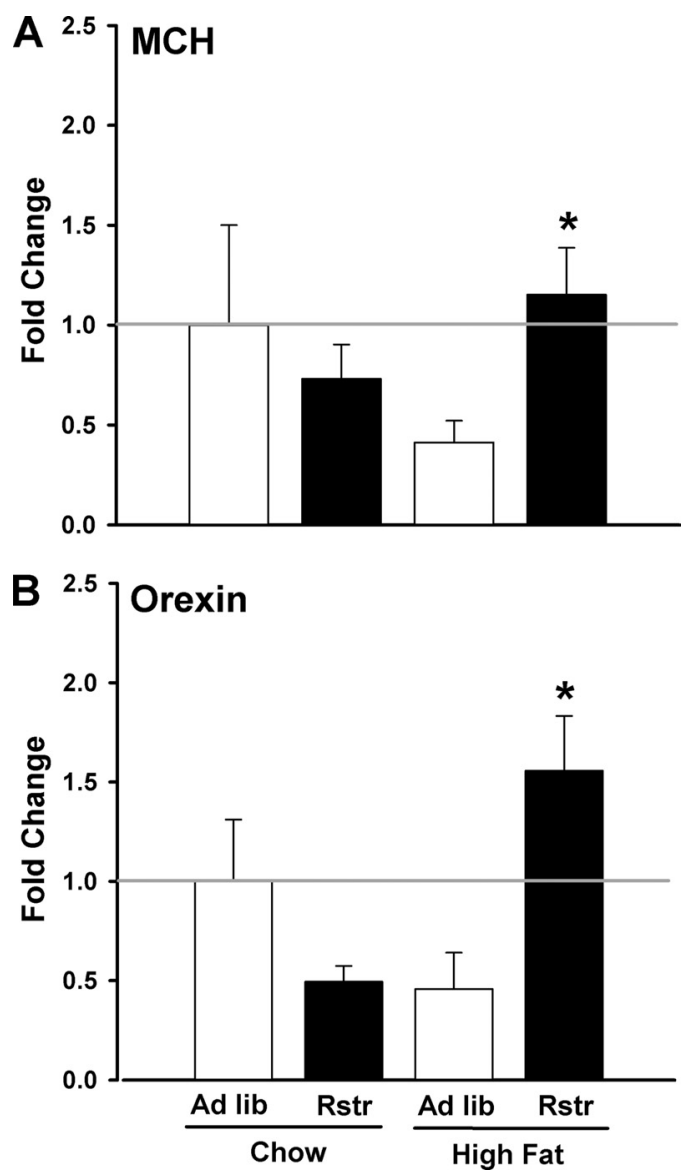

Figure 5. Previous calorie reduction significantly enhances orexigenic hormone responses to high-fat diet. $A, \mathrm{MCH}$ levels in the LH were significantly increased in calorically restricted mice refed on a high-fat diet compared with ad libitum mice refed on high fat $(n=4-5)\left({ }^{*} p<\right.$ $0.05)$. $\boldsymbol{B}$, Orexin levels in the $L$ Here significantly increased in restricted mice refed on a high-fat diet compared with restricted mice refed on chow or ad libitum mice refed on high fat $(n=$ $4-5)\left({ }^{*} p<0.05\right)$. Data are mean \pm SEM.

icantly greater in restricted mice on a high-fat diet compared with ad libitum mice refed on high-fat (post hoc; $p<0.05$ ) (Fig. 5A). Analysis of orexin gene expression revealed an interaction between restriction and diet $\left(F_{(1,12)}=16.577 ; p<0.01\right)$, in which orexin expression was significantly greater in restricted mice on a high-fat diet compared with ad libitum mice refed on high fat $(p<0.05)$ (Fig. 5B).

\section{Reversal of high-fat diet withdrawal induced binge eating} As we hypothesized that previously restricted mice would show a greater sensitivity to an acute treatment with the MCHr1 antagonist GSK-856464, we examined caloric intake and binge eating after high-fat diet exposure and withdrawal stress. As expected, previous restriction increased high-fat binge eating over $3 \mathrm{~d}$ of limited access $\left(F_{(1,185)}=24.652 ; p<0.001\right)$ (Fig. 6). Previous caloric restriction did not increase chow intake (Fig. $6 C$ ) or total caloric intake (Fig. 6E). There was no effect of any drug on high-
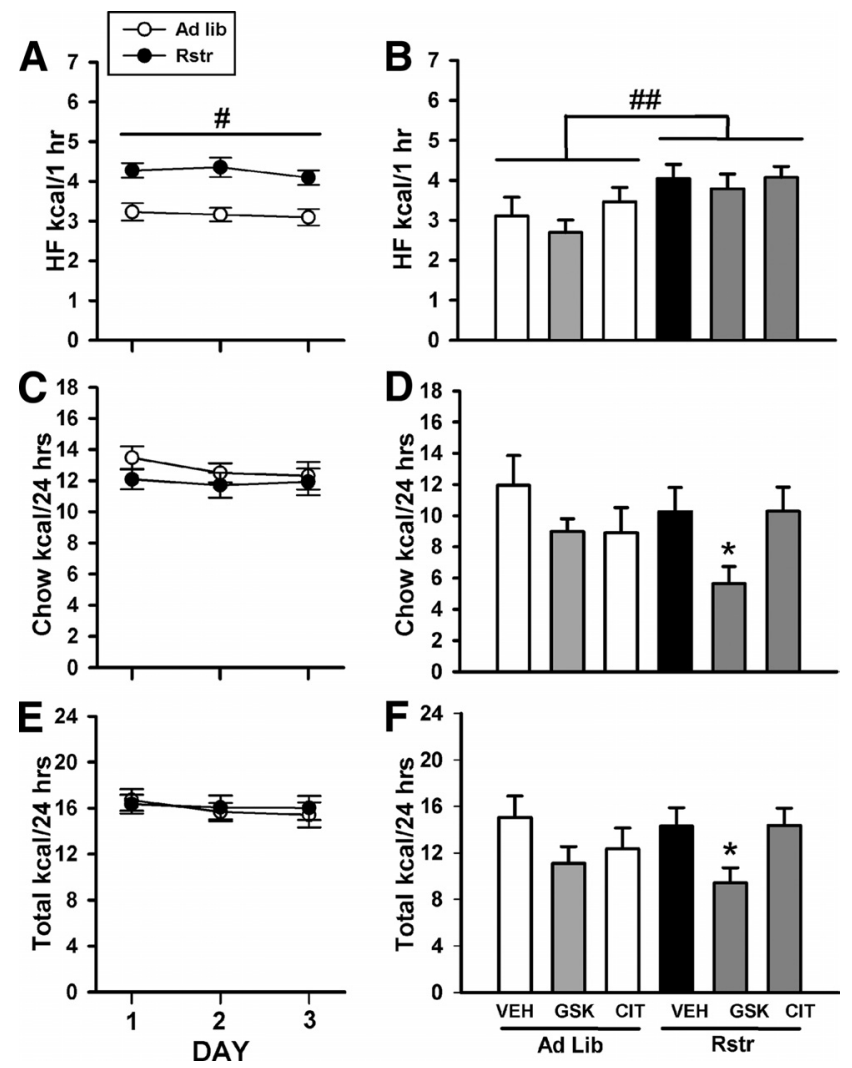

Figure 6. MCHr1 antagonist reduced caloric intake in calorically restricted mice after highfat diet withdrawal. $\boldsymbol{A}, \boldsymbol{C}, \boldsymbol{E}$, During $3 \mathrm{~d}$ limited access to a high-fat pellet, mice previously calorically restricted (Rstr) show increased binge-like consumption of high-fat diet compared with controls (ad libitum) $\left({ }^{\#} p<0.001\right)$. (A) but not differences in $24 \mathrm{~h}$ chow $(\boldsymbol{C})$ or total calories $(\boldsymbol{E}) . \boldsymbol{B}$, On the fourth day of testing, increased caloric intake of the high-fat pellet continued in the restricted mice ( ${ }^{\# \#} p<0.01$ ). However, there was no effect of drug on high-fat caloric intake. D, The MCHr1 antagonist, GSK-856464, reduced chow caloric intake only in previously CR mice $\left({ }^{*} p<0.05\right)$. $\boldsymbol{F}$, The MCHr1 antagonist, GSK-856464, significantly reduced overall caloric intake only in previously CR mice ( ${ }^{*} p<0.05$ ) (ad libitum-VEH, $n=7$; ad libitum-GSK, $n=8$; ad libitum-CIT, $n=8$; Rstr-VEH, $n=8$; Rstr-GSK, $n=8$; Rstr-CIT, $n=8$ ). Data are mean \pm SEM.

fat caloric intake on the fourth day of limited access; however, the effect of restriction remained with previously calorically restricted mice having a greater caloric intake of the high-fat pellet compared with controls $\left(F_{(1,41)}=9.072 ; p<0.01\right)$ (Fig. $6 B$ ). Twenty-four hour chow intake was significantly changed by drug treatment $\left(F_{(2,41)}=3.678 ; p<0.05\right)$ with post hoc tests revealing a significant decrease in chow caloric intake in previously restricted mice treated with the MCHr1 antagonist, GSK-856464 $(p<0.05)$ (Fig. 6D). Twenty-four hour total caloric intake was significantly changed by drug treatment $\left(F_{(2,41)}=4.128 ; p<\right.$ 0.05 ) with post hoc tests revealing a significant decrease in chow caloric intake in previously restricted mice treated with GSK$856464(p<0.05)$ (Fig. 6F).

\section{Discussion}

Dieting failure and consequent weight regain result in an elevated risk for obesity and metabolic disease (Guagnano et al., 2000; Amigo and Fernández, 2007). Determining potential long-term effects of caloric restriction on programming of stress pathways may identify mechanisms contributing to treatment resistance. We have examined the behavioral and physiological stress state, changes in CRF gene expression and DNA methylation, and the consequent vulnerability to stress-induced binge eating pro- 
duced after moderate calorie reduction in mice. Although a majority of studies examining outcomes of caloric restriction have focused on its beneficial effects on longevity in organisms ranging from Drosophila to rodents and nonhuman primates, examination of the stress sensitivity during caloric restriction has been neglected (Bishop and Guarente, 2007; Levenson and Rich, 2007). Unlike experimental animals, humans do not usually live in a restricted environment, thereby making examination of stress state important in determining the long-term treatment success and potential factors that may contribute to dieting failure.

\section{Caloric restriction reprograms stress pathways}

In our study, calorically restricted mice lost $10-15 \%$ of their body weight over 3 weeks compared with ad libitum control mice, weight loss typical of that obtained during behavioral modification and dieting in humans (Sarwer et al., 2009). To examine the stress state produced during caloric restriction, physiological and behavioral stress responses were measured. In a tail suspension test, calorically restricted mice showed a significant increase in time spent immobile compared with control mice, supportive of an increase in depressive-like behavior (Holmes et al., 2002). Studies that have used a more severe restriction that produced a greater and more rapid weight loss have reported increased swimming behavior in a forced swim test in mice, suggesting that there may be underlying mechanistic differences in central responses between moderate and more severe weight loss (Lutter et al., 2008a,b).

Similar to the increased stress sensitivity detected in the tail suspension test, calorically restricted mice also showed significantly increased corticosterone levels after an acute 15 min restraint stress with a higher maximal rise and a delayed stress recovery. Similar results have been shown in rats that were food restricted to $90 \%$ of initial body weight (Marinelli et al., 1996). As these studies were conducted in C57BL/6 mice, a low stress responding strain (as shown by the low rise in corticosterone in control mice), the magnitude of increased corticosterone levels produced after calorie reduction supports a profound impact of a moderate reduction in caloric availability that is translated into heightened physiological stress responsivity (Goel and Bale, 2007, 2008). Individuals with affective disorders typically present with increased stress sensitivity and HPA axis dysregulation supporting that dieting in humans may promote a period in which the acute and long-term stress state becomes a key factor in continued treatment outcome and maintenance (Pariante and Lightman, 2008; Gallagher et al., 2009).

As the key conductor in the orchestration of stress responsivity, CRF expression was analyzed after caloric restriction in the $\mathrm{CeA}$ and BNST, regions of the limbic system distinct in their efferent and afferent projections (Swanson et al., 1983). Although CRF in the CeA was unchanged, CRF in the BNST was significantly decreased. To determine whether these effects would be maintained during ad libitum refeeding, CRF was again measured once mice had attained normalized body weights. Surprisingly, BNST CRF expression remained significantly reduced, suggesting a possible epigenetic programming in response to caloric restriction. Therefore, we examined the DNA methylation of the characterized CpG island in the CRF promoter (McGill et al., 2006; Mueller and Bale, 2008). Similar to the CRF expression, CRF methylation changes were brain region specific in which caloric restriction produced a significant change in methylation in the BNST, but no effect was detected in the CeA. Furthermore, methylation patterns were not ameliorated during refeeding. In previous studies, we reported similar increases in stress responsivity in a model of high-fat diet withdrawal (Teegarden and Bale, 2007). As reductions in diet palatability and fat content are additional components of dieting, we examined CRF expression and promoter methylation in mice after exposure and subsequent withdrawal from a high-fat diet. To determine whether the withdrawal effects persisted, we analyzed expression at multiple points over 8 weeks. In the CeA, we observed peak expression of CRF at 2 weeks after withdrawal, and a return to baseline around 6 weeks. Increased CRF levels in the CeA have been correlated with diet cycling and relapse to compulsive eating (Cottone et al., 2009). Interestingly, CRF expression in the BNST decreased with high-fat diet exposure and remained unchanged after withdrawal. Examination of promoter methylation showed an overall decrease in methylation in the BNST, but not in the CeA. Although high-fat diet exposure reduced CRF expression in the BNST similar to that seen with withdrawal, only the withdrawal produced a significant change in promoter methylation, suggesting that distinct transcriptional mechanisms are involved in regulating CRF in the BNST. The brain region-specific changes in CRF expression and promoter methylation were similar between caloric restriction and high-fat withdrawal, indicating that increased stress sensitivity may be a common component regardless of the method used to lose weight.

Recent studies have identified novel roles for methyl binding proteins such as $\mathrm{MeCP} 2$ (methyl $\mathrm{CpG}$ binding protein 2) to recruit transcription machinery and activate rather than suppress transcription (Chahrour et al., 2008). As we detected reduced methylation within the CRF promoter, these results support long-term epigenetic regulation of CRF after caloric restriction and high-fat withdrawal. CRF containing GABAergic neurons in the BNST project to and inhibit the paraventricular hypothalamic nucleus (PVN) (Cullinan et al., 1993). Therefore, a reduced inhibition may be contributing to the increased HPA axis responsivity detected in these calorically restricted mice.

\section{Caloric restriction reprograms orexigenic pathways and promotes binge eating}

Stress pathways have a major influence on motivational behaviors via their intersection with brain reward centers (Self and Nestler, 1998; Koob, 2009). Stress experience increases drugseeking behaviors as well as the motivation for natural rewards, including palatable calorically dense foods (Kelley et al., 2005; Teegarden and Bale, 2007; Foster et al., 2009; Shalev et al., 2010). To examine a long-term behavioral consequence of previous restriction, we examined binge eating of a high-fat food during stress exposure in these mice (Teegarden and Bale, 2008). As predicted, stress-sensitive previously restricted mice consumed significantly more of the high-fat food compared with stressed ad libitum mice. During the limited access testing, all mice displayed binge eating, consuming $\sim 50 \%$ of their total $24 \mathrm{~h}$ intake of calories during the $1 \mathrm{~h}$ of access supporting the high preference mice have for the high-fat diet.

To determine a potential underlying mechanism for the increased binge eating of the high-fat food during stress in previously restricted mice, expression of the orexigenic hormones $\mathrm{MCH}$ and orexin was examined. Intriguingly, although orexigenic hormones were reduced in control animals during exposure to high fat, previously restricted mice showed robust increases in both genes (Beck et al., 2006; Teegarden et al., 2008). $\mathrm{MCH}$ and orexin interact with the mesolimbic dopamine system and are thought to promote the motivational behaviors associated with increased consumption of calorically dense and pre- 
ferred foods (Georgescu et al., 2005; Peciña et al., 2006; Borgland et al., 2009; Zheng et al., 2009; Sears et al., 2010). Thus, atypical elevations in these orexigenic hormones in response to a high-fat calorically dense diet in previously restricted mice, combined with long-term changes in stress sensitivity, likely contribute to the stress-induced binge eating detected in these animals (Shalev et al., 2010).

Previous studies have demonstrated that stress-induced reinstatement of rewarding substances, including high-fat food, can be blunted by administration of MCHr1 antagonist (Chung et al., 2009). In addition, high-fat food-reinforced operant responding was also reduced after MCHrl antagonist treatment (Nair et al., 2009). Therefore, we hypothesized that previously restricted mice based on their dysregulation of stress and orexigenic pathways would show a greater sensitivity to an acute treatment with the MCHr1 antagonist GSK-856464. We examined caloric intake and binge eating after high-fat diet exposure and withdrawal stress. As expected, previously restricted mice showed an increase in high-fat binge eating compared with ad libitum controls. Furthermore, acute GSK-856464 treatment significantly reduced overall caloric intake in previously restricted mice, supporting our hypothesis that these mice would show a greater sensitivity to $\mathrm{MCH}$ antagonism. Acute treatment with the SSRI citalopram did not produce an effect on food intake in these studies, suggesting that the central programming changes produced after caloric restriction may not involve serotonergic pathways.

Together, these results suggest that the stress associated with moderate caloric restriction promotes long-term alterations in genes critical in feeding and reward circuitry that influence food intake and stress-related behaviors. These changes may in part be driven by epigenetic mechanisms promoting increased sensitivity of stress pathways that project to and alter reward circuitry. Such epigenetic mechanisms likely hold an evolutionary advantage in times of famine, but in our current environment of high caloric availability would function against our health and contribute to difficulty in weight management. It seems appropriate that the brain developed strategies to guard against loss of calories by increasing the likelihood that a previous restriction experience would promote future behaviors to increase consumption of calorically dense foods.

\section{References}

Amigo I, Fernández C (2007) Effects of diets and their role in weight control. Psychol Health Med 12:321-327.

Beck B, Kozak R, Moar KM, Mercer JG (2006) Hypothalamic orexigenic peptides are overexpressed in young Long-Evans rats after early life exposure to fat-rich diets. Biochem Biophys Res Commun 342:452-458.

Bishop NA, Guarente L (2007) Genetic links between diet and lifespan: shared mechanisms from yeast to humans. Nat Rev Genet 8:835-844.

Borgland SL, Chang SJ, Bowers MS, Thompson JL, Vittoz N, Floresco SB, Chou J, Chen BT, Bonci A (2009) Orexin A/hypocretin-1 selectively promotes motivation for positive reinforcers. J Neurosci 29:1121511225.

Brownell KD, Rodin J (1994) Medical, metabolic, and psychological effects of weight cycling. Arch Intern Med 154:1325-1330.

Chahrour M, Jung SY, Shaw C, Zhou X, Wong ST, Qin J, Zoghbi HY (2008) $\mathrm{MeCP} 2$, a key contributor to neurological disease, activates and represses transcription. Science 320:1224-1229.

Chung S, Hopf FW, Nagasaki H, Li CY, Belluzzi JD, Bonci A, Civelli O (2009) The melanin-concentrating hormone system modulates cocaine reward. Proc Natl Acad Sci U S A 106:6772-6777.

Cottone P, Sabino V, Roberto M, Bajo M, Pockros L, Frihauf JB, Fekete EM, Steardo L, Rice KC, Grigoriadis DE, Conti B, Koob GF, Zorrilla EP (2009) CRF system recruitment mediates dark side of compulsive eating. Proc Natl Acad Sci U S A 106:20016-20020.

Cullinan WE, Herman JP, Watson SJ (1993) Ventral subicular interaction with the hypothalamic paraventricular nucleus: evidence for a relay in the bed nucleus of the stria terminalis. J Comp Neurol 332:1-20.

Dallman MF, Pecoraro NC, la Fleur SE (2005) Chronic stress and comfort foods: self-medication and abdominal obesity. Brain Behav Immun 19: 275-280.

Dallman MF, Pecoraro NC, La Fleur SE, Warne JP, Ginsberg AB, Akana SF, Laugero KC, Houshyar H, Strack AM, Bhatnagar S, Bell ME (2006) Glucocorticoids, chronic stress, and obesity. Prog Brain Res 153:75-105.

Epel E, Lapidus R, McEwen B, Brownell K (2001) Stress may add bite to appetite in women: a laboratory study of stress-induced cortisol and eating behavior. Psychoneuroendocrinology 26:37-49.

Erb S, Stewart J (1999) A role for the bed nucleus of the stria terminalis, but not the amygdala, in the effects of corticotropin-releasing factor on stressinduced reinstatement of cocaine seeking. J Neurosci 19:RC35(1-6).

Foster MT, Warne JP, Ginsberg AB, Horneman HF, Pecoraro NC, Akana SF, Dallman MF (2009) Palatable foods, stress, and energy stores sculpt corticotropin-releasing factor, adrenocorticotropin, and corticosterone concentrations after restraint. Endocrinology 150:2325-2333.

Gallagher P, Reid KS, Ferrier IN (2009) Neuropsychological functioning in health and mood disorder: modulation by glucocorticoids and their receptors. Psychoneuroendocrinology 34 [Suppl 1]:S196-S207.

Georgescu D, Sears RM, Hommel JD, Barrot M, Bolaños CA, Marsh DJ, Bednarek MA, Bibb JA, Maratos-Flier E, Nestler EJ, DiLeone RJ (2005) The hypothalamic neuropeptide melanin-concentrating hormone acts in the nucleus accumbens to modulate feeding behavior and forced-swim performance. J Neurosci 25:2933-2940.

Ghitza UE, Gray SM, Epstein DH, Rice KC, Shaham Y (2006) The anxiogenic drug yohimbine reinstates palatable food seeking in a rat relapse model: a role of CRF1 receptors. Neuropsychopharmacology 31:2188-2196.

Goel N, Bale TL (2007) Identifying early behavioral and molecular markers of future stress sensitivity. Endocrinology 148:4585-4591.

Goel N, Bale TL (2008) Organizational and activational effects of testosterone on masculinization of female physiological and behavioral stress responses. Endocrinology 149:6399-6405.

Guagnano MT, Ballone E, Pace-Palitti V, Vecchia RD, D’Orazio N, Manigrasso MR, Merlitti D, Sensi S (2000) Risk factors for hypertension in obese women. The role of weight cycling. Eur J Clin Nutr 54:356-360.

Holmes A, Yang RJ, Murphy DL, Crawley JN (2002) Evaluation of antidepressant-related behavioral responses in mice lacking the serotonin transporter. Neuropsychopharmacology 27:914-923.

Kelley AE, Baldo BA, Pratt WE (2005) A proposed hypothalamic-thalamicstriatal axis for the integration of energy balance, arousal, and food reward. J Comp Neurol 493:72-85.

Kim HR, Hwang KA, Kim KC, Kang I (2007) Down-regulation of IL-7R $\alpha$ expression in human $\mathrm{T}$ cells via DNA methylation. J Immunol 178:5473-5479.

Koob GF (2009) Brain stress systems in the amygdala and addiction. Brain Res 1293:61-75.

Levenson CW, Rich NJ (2007) Eat less, live longer? New insights into the role of caloric restriction in the brain. Nutr Rev 65:412-415.

Lissner L, Odell PM, D’Agostino RB, Stokes J 3rd, Kreger BE, Belanger AJ, Brownell KD (1991) Variability of body weight and health outcomes in the Framingham population. N Engl J Med 324:1839-1844.

Liu T, Zhang X, So CK, Wang S, Wang P, Yan L, Myers R, Chen Z, Patterson AP, Yang CS, Chen X (2007) Regulation of Cdx2 expression by promoter methylation, and effects of $\mathrm{Cdx} 2$ transfection on morphology and gene expression of human esophageal epithelial cells. Carcinogenesis 28:488-496.

Lutter M, Krishnan V, Russo SJ, Jung S, McClung CA, Nestler EJ (2008a) Orexin signaling mediates the antidepressant-like effect of calorie restriction. J Neurosci 28:3071-3075.

Lutter M, Sakata I, Osborne-Lawrence S, Rovinsky SA, Anderson JG, Jung S, Birnbaum S, Yanagisawa M, Elmquist JK, Nestler EJ, Zigman JM (2008b) The orexigenic hormone ghrelin defends against depressive symptoms of chronic stress. Nat Neurosci 11:752-753.

Marinelli M, Le Moal M, Piazza PV (1996) Acute pharmacological blockade of corticosterone secretion reverses food restriction-induced sensitization of the locomotor response to cocaine. Brain Res 724:251-255.

McEuen JG, Semsar KA, Lim MA, Bale TL (2009) Influence of sex and corticotropin-releasing factor pathways as determinants in serotonin sensitivity. Endocrinology 150:3709-3716. 
McGill BE, Bundle SF, Yaylaoglu MB, Carson JP, Thaller C, Zoghbi HY (2006) Enhanced anxiety and stress-induced corticosterone release are associated with increased Crh expression in a mouse model of Rett syndrome. Proc Natl Acad Sci U S A 103:18267-18272.

Mendoza J (2007) Circadian clocks: setting time by food. J Neuroendocrinol 19:127-137.

Mueller BR, Bale TL (2008) Sex-specific programming of offspring emotionality after stress early in pregnancy. J Neurosci 28:9055-9065.

Nair SG, Adams-Deutsch T, Pickens CL, Smith DG, Shaham Y (2009) Effects of the MCH1 receptor antagonist SNAP 94847 on high-fat foodreinforced operant responding and reinstatement of food seeking in rats. Psychopharmacology (Berl) 205:129-140.

Pariante CM, Lightman SL (2008) The HPA axis in major depression: classical theories and new developments. Trends Neurosci 31:464-468.

Paxinos G, Franklin KBJ (2001) The mouse brain in stereotaxic coordinates, Ed 2. San Diego: Academic.

Peciña S, Schulkin J, Berridge KC (2006) Nucleus accumbens corticotropinreleasing factor increases cue-triggered motivation for sucrose reward: paradoxical positive incentive effects in stress? BMC Biol 4:8.

Redman LM, Heilbronn LK, Martin CK, Alfonso A, Smith SR, Ravussin E (2007) Effect of calorie restriction with or without exercise on body composition and fat distribution. J Clin Endocrinol Metab 92:865-872.

Sarwer DB, von Sydow Green A, Vetter ML, Wadden TA (2009) Behavior therapy for obesity: where are we now? Curr Opin Endocrinol Diabetes Obes 16:347-352.

Sears RM, Liu RJ, Narayanan NS, Sharf R, Yeckel MF, Laubach M, Aghajanian GK, DiLeone RJ (2010) Regulation of nucleus accumbens activity by the hypothalamic neuropeptide melanin-concentrating hormone. J Neurosci 30:8263-8273.
Self DW, Nestler EJ (1998) Relapse to drug-seeking: neural and molecular mechanisms. Drug Alcohol Depend 51:49-60.

Shaham Y, Erb S, Stewart J (2000) Stress-induced relapse to heroin and cocaine seeking in rats: a review. Brain Res Brain Res Rev 33:13-33.

Shalev U, Erb S, Shaham Y (2010) Role of CRF and other neuropeptides in stress-induced reinstatement of drug seeking. Brain Res 1314:15-28.

Sinha R (2001) How does stress increase risk of drug abuse and relapse? Psychopharmacology (Berl) 158:343-359.

Swanson LW, Sawchenko PE, Rivier J, Vale WW (1983) Organization of ovine corticotropin-releasing factor immunoreactive cells and fibers in the rat brain: an immunohistochemical study. Neuroendocrinology 36:165-186.

Teegarden SL, Bale TL (2007) Decreases in dietary preference produce increased emotionality and risk for dietary relapse. Biol Psychiatry 61: 1021-1029.

Teegarden SL, Bale TL (2008) Effects of stress on dietary preference and intake are dependent on access and stress sensitivity. Physiol Behav 93:713-723.

Teegarden SL, Nestler EJ, Bale TL (2008) Delta FosB-mediated alterations in dopamine signaling are normalized by a palatable high-fat diet. Biol Psychiatry 64:941-950

Wang B, Shaham Y, Zitzman D, Azari S, Wise RA, You ZB (2005) Cocaine experience establishes control of midbrain glutamate and dopamine by corticotropin-releasing factor: a role in stress-induced relapse to drug seeking. J Neurosci 25:5389-5396.

Wing RR, Phelan S (2005) Long-term weight loss maintenance. Am J Clin Nutr 82:222S-225S.

Zheng H, Lenard NR, Shin AC, Berthoud HR (2009) Appetite control and energy balance regulation in the modern world: reward-driven brain overrides repletion signals. Int J Obes (Lond) 33 [Suppl 2]:S8-S13. 